\title{
Optimasi Percepatan Durasi Proyek Pembangunan Gedung
}

\author{
Parea Rusan R * \\ *Teknik Sipil, Fakultas Teknik, Universitas Kristen Indonesia Toraja, \\ parea@ukitoraja.ac.id
}

\begin{abstract}
Pada suatu proyek konstruksi jadwal dan rencana kerja merupakan hal yang penting. Dalam suatu proyek konstruksi hampir selalu terjadi perubahan rencana dari yang telah ditetapkan semula, dimana perubahan rencana tersebut bisa terjadi sebelum proyek dimulai ataupun pada saat proyek sedang berlangsung.

Pada studi kasus dibahas Proyek Pembangunan Gedung Olahraga di kota Rantepao, dengan Biaya Proyek sebesar Rp Rp1.188.195.378 dan masa pelaksanaan proyek selama 210 hari kerja.

Hasil analisa menggunakan metode Least Cost Analysis, penyelesaian proyek tercepat yang dapat diterapkan untuk menyelesaikan proyek pembangunan gedung olahraga di kota Rantepao dengan penambahan jam kerja adalah 199 hari, 11 hari lebih cepat dari waktu penyelesaian rencana awal, dengan pengurangan biaya total proyek sebesar Rp. 50.728.327,00, sedangkan dengan menggunakan metode penambahan tenaga kerja adalah mempercepat proyek 188 hari, 22 hari lebih cepat dari waktu penyelesaian rencana awal, dengan pengurangan biaya total proyek sebesar Rp. 50.736.720,00 dan dengan menggunakan metode penambahan peralatan mempercepat proyek 195 hari, 15 hari lebih cepat dari waktu penyelesaian rencana awal, dengan pengurangan biaya total proyek sebesar Rp. 52.064.076,00.
\end{abstract}


Keywords- Least Cost Analysis, Least cost scheduling, Waktu, Biaya, duration cost trade off, Biaya Langsung, Biaya Tidak Langsung.

\section{Pendahuluan}

\subsection{Latar Belakang Masalah}

Pembangunan gedung dibuat dengan membuat perencanaan pada awal rencana proyek, sehingga pada saat itulah ditentukan jenis gedung serta manfaat yang di inginkan oleh pemilik gedung .semua itu berpengaruh terhadap faktor - faktor teknis, seperti methode pelaksanaan, alokasi biaya, alokasi bahan atau material, alokasi tenaga kerja, perencanaan waktu dan bagaimana proses pengendaliannya.

Setiap proyek memiliki tujuan khususdalam proses mencapai tujuan tersebut di tentukan oleh 3 aspek yaitu besar biaya (anggaran) yang dialokasikan dan jadwal serta mutu yang harus dipenuhi serta saling berkaitan dan saling mempengaruhi satu dengan yang lainnya.

Dalam pelaksanaan proyek konstruksi seringkali durasi proyek di percepat karena kondisi tertentu, misalkan pemilik proyek mungkin menginginkan agar proyek dapat selesai lebih awal dari rencana semula atau pemilik akan memberikan bonus jika proyek selesai lebih awal dari rencana. Bahkan sebuah proyek yang sedang berjalan dan ternyata progress terlambat dari rencana, maka perlu dilakukan usaha untuk mengembalikan progress rencana semula.Untuk kebutuhan tersebut perlu dilakukan usaha percepatan waktu setiap kegiatan, guna mencapai progress yang direncanakan pada awal rencana. Usaha untuk mempercepat waktu setiap kegiatan dapat dilakukan 
diantaranya dengan menambah jumlah tenaga kerja atau menambah jumlah jam atau jam lembur.

Proyek konstruksi hanya mungkin diperpendek dengancara mengurangi panjang lintasan kritis dengan menerapkan upaya - upaya tambahan pada kegiatan - kegiatan di sepanjang lintasan kritis sehingga rentang waktunya secara keseluruhan dapat dikurangi. Untuk itu perlu dilakukan pengujian adanya kemungkinan kegiatan yang dapat dikurangi rentang waktunya dengancara menerapkan upaya - upaya tambahan dengan konsekuensi diikuti tambahan biaya.

Permasalahan yang dihadapi adalah sebagai berikut bagaimana durasi waktu dan biaya pekerjaan pembangunan Gedung Olahraga Jayata Bolu, dan bagaimana perbandingan durasi pekerjaan dan biaya setelah di adakan percepatan menggunakan Metode Least Cost Analysis dengan metode sebelumnya?

\section{Figures and Tables}

\subsection{Proyek}

Proyek dapat diartikan sebagai suatu kegiatan yang berlangsung dalam jangka waktu tertentu dengan alokasi sumber daya terbatas dan dimaksudkan untuk melaksanakan suatu tugas yang telah di gariskan ( Imam, 1992 ).

Analisis optimasi dipecah menjadi 2 pengertian yaitu analisis dan optimasi. Analisis (Analisis Data) diartikan sebagai “penelaah danpenguraian atas data hingga menghasilkan simpulan - simpulan".Optimasi (Optimalisasi) diartikan sebagai pengoptimalan, yaitu " proses, cara, perbuatan untuk menghasilkan yang paling baika”. Berdasarkan pengertian analisis dan optimasi dari Kamus Besar Bahasa Indonesia tersebut disimpulkan bahwa analisis optimasi merupakan suatu proses penguraian data - data awal menggunakan suatu metode untuk mendapatkan simpulan yang paling baik dibandingkan dengan menggunakan metode sebelumnya. 


\subsection{Least Cost Analysis}

Untuk mengatasi ketidak sesuaian durasi proyek dan berbagai kendala yang mungkin terjadi biasanya dilakukan penyesuaian durasi proyek. Pendekatan yang dapat digunakan untuk melakukan penyesuaian durasi proyek adalah dengan pendekatan Duration- Cost Trade - off yang dilakukan dengan Project Cashing dan Least Cost Analysis.

Duration- Cost Trade - off adalah suatu metode untuk menentukan besarnya biaya yang harus dibayar untuk menggantikan durasi pekerjaan (Leny, 2001 ) ( Willis, 1986 ) dalam ( Leny, 2001 ) mengatakan bahwa project cashing merupakan " suatu analysis memperoleh biaya langsung yang minimal dari usaha mempersingkat waktu penyelesaian proyek menjadi durasi tertentu.

Least Cost Analysis adalah suatu analysis untuk memperoleh durasi proyek yang optimal yaitu durasi dengan biaya total minimal. Untuk melakukan Least Cost Analysis harus didefenisikan dulu biaya langsung dan tidak langsung, tahap dalam Least Cost Analysis yaitu melakukan pengurangan durasi kegiatan - kegiatan yang memiliki pertambahan biaya terkecil sampai terbesar secara berurutan. Jika durasi proyek berkurang maka biaya langsung akan bertambah (naik) secara contiunue sebesar biaya untuk melaksanakan kerja lembur untuk kegiatan yang durasinya dipendekkan, secara biaya tidak langsung akan berkurang secara linier tergantung besarnya durasi pengurangan.

\section{Metode Penelitian}

\subsection{Tujuan Khusus Penelitian}

Tujuan penelitian ini bertujuan untuk melihat sejauh mana durasi proyek normal dan berapa percepatan durasi proyek yang dapat dilaksanakan serta mengetahui berapa durasi proyek optimal dan berapa biaya optimumnya yang akan di teliti pada proyek Pembangunan Gedung Olahraga di kota Rantepao.

\subsection{Metode Penelitian}

Penelitian ini dilakukan dengan menggunakan metode penelitian kualitatif yaitu metode penelitian yang berlandaskan pada filsafat postpositivisme, digunakan untuk meneliti pada kondisi obyek yang alamiah dimana peneliti 
adalah sebagai instrument kunci, pengambil sampel sumber data dilakukan secara Purposive Sampling.

\subsection{BaganAlirPenelitian}

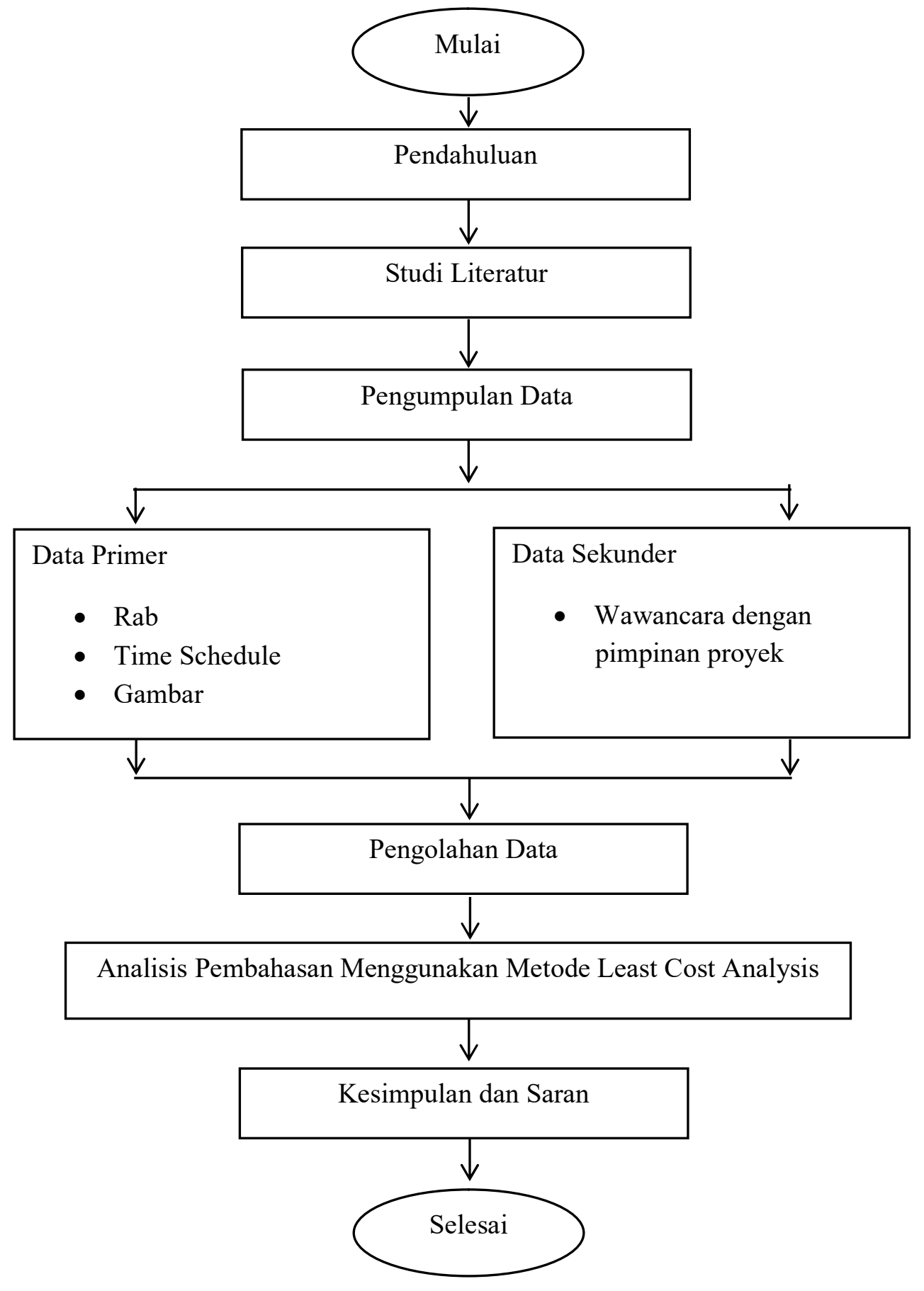




\section{Gambar 3.3 Bagan Alir Penelitian}

\section{BAB IV. ANALISA DAN PEMBAHASAN}

\subsection{Deskripsi Proyek}

Nama Proyek $\quad$ : Pembangunan Gedung Olahraga Jayata Bolu

Pemilik Proyek : Samli Buntuan

Alamat Proyek $\quad$ : kompleks Pasar Bolu Rantepao (Samping Masjid)

Kabupaten Toraja Utara - Sulawesi Selatan

Nilai Kontrak $\quad$ : Rp1.188.195.378

Setelah didapatkan hubungan antara aktivitas dan durasi masing - masing aktivitas, maka langkah selanjutnya yaitu melakukan perhitungan Cost Slope

Dalam Perhitungan Cost Slope Harus diketahui terlebih dahulu durasi normal dari data proyek yang telah di peroleh.

\subsection{Perhitungan Biaya Percepatan (Cost Slope)}

Dengan adanya percepatan durasi pelaksanaan pada aktivitas tertentu, maka akan terjadi pertambahan biaya akibat percepatan durasi tersebut. Pertambahan biaya percepatan tersebut tergantung besarnya durasi percepatan yang direncanakan serta total biaya setelah percepatan (crash cost). Semakin besar crash costnya, maka akan semakin besar nilai cost slopenya. Dalam perhitungan cost slope terdapat 3 alternatif yaitu :

1. Penambahan peralatan

2. Penambahan tenaga kerja

3. Penambahan jam kerja (lembur).

Dari ketiga alternatif di atas penulis mengambil alternatif yang ke tiga yaitu Penambahan Jam Kerja (Lembur)

I. Penambahan Jam Kerja

Asumsi yang digunakan untuk penambahan jam kerja adalah sebagai berikut : 
1. Dalam 1 hari aktivitas normal 7 jam dan 1 jam istirahat $(08.00-16.00$ WIB), sedangkan kerja lembur dilakukan setelah waktu kerja normal ( 17.00 - 21.00), yaitu 2 jam/hari.

2. Produktivitas untuk kerja lembur diperhitungkan $80 \%$ dari produktivitas normal.

II. Perhitungan Cost Slope item pekerjaan yang akan dipercepat yaitu $\boldsymbol{F}-\boldsymbol{G}-$ $\boldsymbol{J}:$

A. Penambahan Jam Kerja ( Lembur )

\section{Pekerjaan Konstruksi Baja dan Atap (F)}

\section{a. Kolom WF $200 \times 100 \times 5.5 \times 8$}

$\bullet$

a.

b.

c.

d.

e. Produktifitas dengan penambahan 3 jam kerja

f. Produktifitas harian setelah crash :

$=$ Produktifitas Hari $+($ Penambahan Jam Kerja $\mathrm{x}$ $80 \%$ x Produktifitas Jam )

$=938,6+(3 \times 0,8 \times 134)$

=1260,2 Perhitungan Crash Duration

Crash Duration $=$ Volume $/$ Produktivitas Penambahan Jam Kerja

$=2816 / 1260,2$

$=2,23=2$

- $\quad$ Perhitungan Crash Cost

Crash Cost $=($ Normal Cost $/$ Normal Duration $\mathrm{x}$ Crash Duration $)+($ Aktivitas Normal x Produk tivitas penambahan jam kerja x Durasi Crash ) $=(43.648 .000 / 3 \times 2)+(7 \times 1153 \times 2)$ 


$$
\begin{aligned}
& \begin{aligned}
\text { Crash Cost }=29.098 .666+305,76 \\
=\text { Rp. } 29.114 .808,00
\end{aligned} \\
& \text { Jadi Crash Cost adalah }=\text { Rp. } 29.114 .808,00 \\
& \text { Cost Slope }=\frac{\text { Crash Cost }- \text { Normal Cost }}{\text { Normal Duration-Crash Duration }} \\
& \text { Cost Slope }=\frac{29.114 .808-4 \Sigma .648 .000}{3-2} \\
& \text { Cost Slope }=- \text { Rp. 14. 533.192,00 }
\end{aligned}
$$

\section{B. Penambahan Peralatan}

\section{Pekerjaan Konstruksi Baja dan Atap (F)}

Dalam penambahan tenaga kerja, penambahan alat bantu seperti skop, palu - palu, sendok tembok dan lain - lain $=100 \mathrm{~m} 3 /$ hari

a. Kolom WF $200 \times 100 \times 5.5 \times 8$

$\bullet$

a.

b.

c.

d.

e.

f.

Produktifitas Harian

a.

Volume $=2816$

Normal Duration $=3$

Produktifitas Harian $=\mathrm{a} / \mathrm{b}=938,6$

Produktifitas tiap jam $=\mathrm{c} / 7=134$

Produktifitas dengan penambahan peralatan

. Produktifitas harian setelah crash :

$=$ Produktifitas Jam + Penambahan Peralatan

$$
=134+100=234 / \mathrm{jam} \times 7=1638 \mathrm{~m} 3 / \text { hari }
$$

- Perhitungan Crash Duration

Crash Duration $=$ Volume $/$ Produktivitas Penambahan Jam Kerja

$$
=2816 / 1638=1,71=
$$

$\bullet$

Perhitungan Crash Cost

Crash Cost $=($ Normal Cost $/$ Normal Duration $\mathrm{x}$ Crash Duration $)+($ Aktivitas Normal x Produk tivitas penambahan tenaga kerja x Durasi Crash )

$=(43.648 .000 / 3 \times 2)+(7 \times 1638 \times 2)$ 


$$
\begin{aligned}
& \text { Crash Cost }=29.098 .666+22932=\text { Rp. 29.121.598,00 } \\
& \text { Jadi Crash Cost adalah }=\text { Rp. } 29.121 .598,00 \\
& \text { Cost Slope }=\frac{\text { Crash Cost }- \text { Normal Cost }}{\text { Normal Duration - Crash Duration }} \\
& \text { Cost Slope }=\frac{29.121 .598,00-43.648,090}{3-2} \\
& \text { Cost Slope }=- \text { Rp. 14. 526. 402,00 }
\end{aligned}
$$

\begin{tabular}{|c|c|}
\hline Pekerjaan & Biaya Langsung \\
\hline Pas. Kolom WF $200 \times 100 \times 5.5 \times 8$ & Rp. 43.638.000,00 \\
\hline Pas. T-Beam 2CNP 100x50x2,3 & Rp. 13. 516.000,00 \\
\hline Pas. Colom Ekstra WF 150x 75 x 5 x 7 & Rp. 17. 174. 000,00 \\
\hline Pas. Rafter WF 200x100x5.5x8 & Rp. 111. 104.000,00 \\
\hline Pas. Lisplang CNP $125 \times 50 \times 20 \times 2.3$ & Rp. 6. 727.000,00 \\
\hline Pas. Frame CNP $75 \times 45 \times 15 \times 2.3$ & Rp. 4. 495. 000,00 \\
\hline Pas. Flashing Zingalume 0,35 & Rp. 2. 860.000,00 \\
\hline Pas. Pemasangan Jaring Futsal & Rp. 24. 552.000,00 \\
\hline Pas. Rubber & Rp. 14. 580. 000 \\
\hline
\end{tabular}

Tabel 4.3 Biaya Langsung Pekerjaan

Tabel. 4.4Koefisien dan Upah Kerja 


\begin{tabular}{|c|c|c|}
\hline Pekerjaan & $\begin{array}{c}\text { Koefisien } \\
\text { Pekerja }\end{array}$ & $\begin{array}{l}\text { Jumlah } \\
\text { Pekerja }\end{array}$ \\
\hline Pas. Kolom WF 200 x 100 × 5.5 x 8 & 0,006 & 5 \\
\hline Pas. T-Beam 2CNP 100x50x2,3 & 0,06 & 7 \\
\hline Pas. Colom Ekstra WF 150x 75 x 5 x 7 & 0,006 & 3 \\
\hline Pas. Rafter WF 200x100x5.5x8 & 0,003 & 7 \\
\hline Pas. Lisplang CNP $125 \times 50 \times 20 \times 2.3$ & 0,06 & 7 \\
\hline Pas. Frame CNP $75 \times 45 \times 15 \times 2.3$ & 0,06 & 6 \\
\hline Pas. Flashing Zingalume 0,35 & 0,2 & 2 \\
\hline Pas. Pemasangan Jaring Futsal & 0,02 & 5 \\
\hline Pas. Rubber & 0,0006 & 5 \\
\hline
\end{tabular}

Tabel. 4.5 Volume Pekerjaan

\begin{tabular}{|l|c|c|}
\hline \multicolumn{1}{|c|}{ Pekerjaan } & Volume & Sat \\
\hline Pas. Kolom WF 200 x 100 x 5.5 x & 2816 & $\mathrm{Kg}$ \\
\hline Pas. T-Beam 2CNP 100x50x2,3 & 872 & $\mathrm{Kg}$ \\
\hline Pas. Colom Ekstra WF 150x 75 x 5 x 7 & 1108 & $\mathrm{Kg}$ \\
\hline
\end{tabular}




\begin{tabular}{|c|c|c|}
\hline Pas. Rafter WF $200 \times 100 \times 5.5 \times 8$ & 7168 & $\mathrm{Kg}$ \\
\hline Pas. Lisplang CNP $125 \times 50 \times 20 \times 2.3$ & 434 & $\mathrm{Kg}$ \\
\hline Pas. Frame CNP $75 \times 45 \times 15 \times 2.3$ & 290 & $\mathrm{Kg}$ \\
\hline Pas. Flashing Zingalume 0,35 & 44 & $\mathrm{Kg}$ \\
\hline Pas. Pemasangan Jaring Futsal & 1116 & M2 \\
\hline Pas. Rubber & 4860 & $\mathrm{Kg}$ \\
\hline
\end{tabular}

Tabel 4.6 Tabel Hasil Perhitungan Percepatan proyek dengan Penambahan Jam Kerja ( Lembur )

\begin{tabular}{|c|c|c|c|c|}
\hline $\begin{array}{c}\text { Pekerjaan yang } \\
\text { dipercepat }\end{array}$ & $\mathrm{DN}$ & Biaya Normal & $\mathrm{CD}$ & Pengurangan Biaya \\
\hline $\begin{array}{l}\text { Pas. Kolom WF } 200 \times \\
100 \times 5.5 \times 8\end{array}$ & 3 & 43. $638.000,00$ & 2 & $14.533 .192,00$ \\
\hline $\begin{array}{l}\text { Pas. T-Beam 2CNP } \\
100 \times 50 \times 2,3\end{array}$ & 7 & 13. 516. 000,00 & 4 & $1.928 .765,00$ \\
\hline $\begin{array}{l}\text { Pas. Colom Ekstra WF } \\
150 \times 75 \times 5 \times 7\end{array}$ & 3 & 17. $174.000,00$ & 2 & $5.723 .928,00$ \\
\hline $\begin{array}{l}\text { Pas. Rafter WF } \\
200 \times 100 \times 5.5 \times 8\end{array}$ & & & & \\
\hline
\end{tabular}




\begin{tabular}{|c|c|c|c|c|}
\hline & 6 & 111. 104.000,00 & 4 & $18.514 .940,00$ \\
\hline $\begin{array}{l}\text { Pas. Lisplang CNP } \\
125 \times 50 \times 20 \times 2.3\end{array}$ & 4 & $6.727 .000,00$ & 3 & $1.681 .424,00$ \\
\hline $\begin{array}{l}\text { Pas. Frame CNP } \\
75 \times 45 \times 15 \times 2.3\end{array}$ & 3 & 4. $495.000,00$ & 2 & $1.498 .141,00$ \\
\hline $\begin{array}{l}\text { Pas. Flashing Zingalume } \\
0,35\end{array}$ & 4 & 2. $860.000,00$ & 3 & $714.716,00$ \\
\hline $\begin{array}{l}\text { Pas. Pemasangan Jaring } \\
\text { Futsal }\end{array}$ & 4 & 24. 552. 000,00 & 3 & $6.133 .221,00$ \\
\hline
\end{tabular}

Tabel 4.7 Biaya Optimal dan Waktu Penyelesaian Proyek dengan Penambahan Jam Kerja ( Lembur )

\begin{tabular}{|c|c|c|c|}
\hline & Durasi Normal & Durasi Percepatan & Selisih \\
\hline Waktu & & & \\
Penyelesaia & 210 hari & 199 hari & 11 hari \\
n Proyek & & & \\
\hline
\end{tabular}




\begin{tabular}{|c|c|c|c|}
\hline $\begin{array}{c}\text { Biaya Total } \\
\text { Proyek }\end{array}$ & Rp. 1.188.195.378,00 & Rp. 1.137.051.654,00 & Rp. 50.728.327,00 \\
& & & \\
\hline
\end{tabular}

Tabel 4.8 Tabel Hasil Perhitungan Percepatan proyek dengan Penambahan Tenaga Kerja

\begin{tabular}{|c|c|c|c|c|}
\hline $\begin{array}{c}\text { Pekerjaan yang } \\
\text { dipercepat }\end{array}$ & $\mathrm{DN}$ & Biaya Normal & $\mathrm{CD}$ & Penguangan Biaya \\
\hline $\begin{array}{l}\text { Pas. Kolom WF } 200 \times \\
100 \times 5.5 \times 8\end{array}$ & 3 & 43. 638. 000,00 & 2 & Rp. 14. 530. 594,00 \\
\hline $\begin{array}{l}\text { Pas. T-Beam 2CNP } \\
100 \times 50 \times 2,3\end{array}$ & 7 & 13. 516. 000,00 & 1 & Rp. 1. 654. 295,00 \\
\hline $\begin{array}{l}\text { Pas. Colom Ekstra WF } \\
150 \times 75 \times 5 \times 7\end{array}$ & 3 & 17. $174.000,00$ & 1 & Rp. 5. $721.976,00$ \\
\hline $\begin{array}{l}\text { Pas. Rafter WF } \\
200 \times 100 \times 5.5 \times 8\end{array}$ & 6 & 111. 104. 000,00 & 3 & Rp. $18.500 .568,00$ \\
\hline $\begin{array}{l}\text { Pas. Lisplang CNP } \\
125 \times 50 \times 20 \times 2.3\end{array}$ & 4 & 6. $727.000,00$ & 1 & Rp. 1. 681.029,00 \\
\hline $\begin{array}{l}\text { Pas. Frame CNP } \\
75 \times 45 \times 15 \times 2.3\end{array}$ & 3 & $4.495 .000,00$ & 1 & Rp. 1. 497.294,00 \\
\hline
\end{tabular}




\begin{tabular}{|l|l|l|l|l|}
\hline & & & & \\
\hline Pas. Flashing Zingalume & & & & \\
0,35 & 4 & $2.860 .000,00$ & 1 & Rp. 1. 017.717,00 \\
\hline Futsal & 4 & $24.552 .000,00$ & 2 & Rp. 6. 133. 247,00 \\
\hline
\end{tabular}

Tabel 4.7 Biaya Optimal dan Waktu Penyelesaian Proyek dengan Penambahan Tenaga Kerja

\begin{tabular}{|c|c|c|c|}
\hline & Durasi Normal & Durasi Percepatan & Selisih \\
\hline $\begin{array}{c}\text { Waktu } \\
\text { Penyelesaia } \\
\text { n Proyek }\end{array}$ & 210 hari & 188 hari & 22 hari \\
\hline $\begin{array}{c}\text { Biaya Total } \\
\text { Proyek }\end{array}$ & Rp. 1.188.195.378,00 & Rp. 1.134.555.654,00 & Rp. 50. 736. 720 \\
\hline
\end{tabular}


Tabel 4.8 Tabel Hasil Perhitungan Percepatan proyek dengan Penambahan Peralatan

\begin{tabular}{|c|c|c|c|c|}
\hline $\begin{array}{c}\text { Pekerjaan yang } \\
\text { dipercepat }\end{array}$ & $\mathrm{DN}$ & Biaya Normal & $\mathrm{CD}$ & Penguangan Biaya \\
\hline $\begin{array}{l}\text { Pas. Kolom WF } 200 \mathrm{x} \\
100 \times 5.5 \times 8\end{array}$ & 3 & 43. 638. 000,00 & 2 & Rp. 14. 526. 402,00 \\
\hline $\begin{array}{l}\text { Pas. T-Beam 2CNP } \\
100 \times 50 \times 2,3\end{array}$ & 7 & 13. $516.000,00$ & 3 & Rp. 1. 929. 187,00 \\
\hline $\begin{array}{l}\text { Pas. Colom Ekstra WF } \\
150 \times 75 \times 5 \times 7\end{array}$ & 3 & 17. $174.000,00$ & 2 & Rp. 5. 718. 325,00 \\
\hline $\begin{array}{l}\text { Pas. Rafter WF } \\
200 \times 100 \times 5.5 \times 8\end{array}$ & 6 & 111. 104. 000,00 & 5 & Rp. 18. 469. 349,00 \\
\hline $\begin{array}{l}\text { Pas. Lisplang CNP } \\
125 \times 50 \times 20 \times 2.3\end{array}$ & 4 & $6.727 .000,00$ & 2 & Rp. 1. 680.238,00 \\
\hline $\begin{array}{l}\text { Pas. Frame CNP } \\
75 \times 45 \times 15 \times 2.3\end{array}$ & 3 & 4. $495.000,00$ & 1 & Rp. 1. 497.585,00 \\
\hline $\begin{array}{l}\text { Pas. Flashing Zingalume } \\
0,35\end{array}$ & 4 & 2. $860.000,00$ & 1 & Rp. 2. $144.286,00$ \\
\hline
\end{tabular}




\begin{tabular}{|l|c|c|c|c|}
\hline Pas. Pemasangan Jaring & & & & \\
Futsal & 4 & $24.552 .000,00$ & 3 & Rp. 6. 128. 784,00 \\
\hline
\end{tabular}

Tabel 4.9 Biaya Optimal dan Waktu Penyelesaian Proyek dengan Penambahan

Peralatan

\begin{tabular}{|c|c|c|c|}
\hline & Durasi Normal & Durasi Percepatan & Selisih \\
\hline Waktu & & & \\
Penyelesaian & 210 hari & 195 hari & 15 hari \\
Proyek & & & \\
\hline Biaya Total & & & Rp. 52. 064. 076,00 \\
\hline
\end{tabular}




\section{BAB V. KESIMPULAN DAN SARAN}

\section{A. KESIMPULAN}

Hasil analisis perhitungan disimpulkan sebagai berikut :

1. Durasi dan Biaya Normal Pembangunan gedung olahraga Jayata Bolu yaitu 210 hari dengan total biaya sebesar Rp. 1. 188. 195. 378,00

2. Dari hasil analisa menggunakan metode Least Cost Analysis, penyelesaian proyek tercepat yang dapat diterapkan untuk menyelesaikan proyek pembangunan gedung olahraga Jayata Bolu dengan penambahan jam kerja adalah 199 hari, 11 hari lebih cepat dari waktu penyelesaian rencana awal, dengan pengurangan biaya total proyek sebesar Rp. 50.728.327,00, sedangkan dengan menggunakan metode penambahan tenaga kerja adalah mempercepat proyek 188 hari, 22 hari lebih cepat dari waktu penyelesaian rencana awal, dengan pengurangan biaya total proyek sebesar Rp. 50.736.720,00 dan dengan menggunakan metode penambahan peralatan mempercepat proyek 195 hari, 15 hari lebih cepat dari waktu penyelesaian rencana awal, dengan pengurangan biaya total proyek sebesar Rp. 52.064.076,00

3. Dari ketiga metode percepatan yang ada didalam metode Least Cost Analysis, metode yang memberikan pengurangan biaya paling minimum/rendah yaitu menggunakan metode penambahan jam kerja ( lembur dengan pengurangan durasi 11 hari dan pengurangan biaya sebesar Rp. 50.728.327,00.

\section{B. SARAN}


1. Dalam analisa percepatan durasi proyek menggunakan metode least cost analysis pada pembangunan gedung olahraga Jayata Bolu, dapat menjadi motivasi dan acauan bagi para konsultan atau kontraktor, karena dengan menggunakan metode tersebut dapat mengurangi durasi dan biaya dari rencana awal proyek.

\section{DAFTAR PUSTAKA}

Amrullah, 2005.Metode Pelaksanaan Persatuan Kegiatan.

Callahan, 1999.Metode Diagram Preseden (PDM) “ Four Logical Relationship “.

Heri, 2002.DurasiProyek“ Jumlah waktu yang diperlukan untuk menyelasaikan kegiatan”.

Heri\&Yushar, 2003.Least Cost Analysis “ untuk memperoleh durasi proyek yang optimal yaitu durasi dengan biaya total optimal.

Imam, 1992.Proyek adalah suatu kegiatan yang berlangsung dalam jangka waktu tertentu dengan alokasi sumber daya terbatas.

Imam, 1999.Tinjauan Biaya Proyek, fixed capital, working capital.

Imam, 1999.Pengendalian Proyek“ Penentuan langkah - langkah untuk pengendalian proyek “

Leny, 2001.Analis Optimasi, Kamus Besar Bahasa Indonesia, Duration - Cost Tradeoff “ metode untuk penentuan besarnya biaya yang harus dibayar untuk penggantian durasi pekerjaan. 
DYNAMIC SAINT

JDS, Jilid III no. 1, Oktober 2017

Munjiati, 2003.Project Life Cycle, Project Initation, Project Implementation, Project

\section{Termination}

Zulian, 1996, Defenisi Proyek“ Defenisi proyek dalam jangka waktu yang terbatas”.

Zulian,1999. Metode Programme Evaluation dan Review Tecnique (PERT). 